\title{
KADAR FENOL TOTAL, AKTIVITAS ANTIOKSIDAN DAN TINGKAT KESUKAAN MINUMAN FUNGSIONAL JELLY YOGHURT SRIKAYA DENGAN PENAMBAHAN KARAGENAN
}

\author{
Resmi Unggul Pratiwi, Ninik Rustanti*) \\ Program Studi Ilmu Gizi Fakultas Kedokteran Universitas Diponegoro \\ J1.Dr.Sutomo No.18, Semarang, Telp (024) 8453708, Email : gizifk@ undip.ac.id
}

\begin{abstract}
Background: High LDL (Low Density Lipoprotein) content was the one of trigger factors of metabolic syndrome. Reduction of LDL content could through antioxidant mechanism. Sweetsop, that had high antioxidant, was treated with fresh cow's milk with carrageenan addition to be a jelly yogurt drink that could be a functional drink as an alternative to decrease the metabolic syndrome risk.

Objective: Analyzing substitution influence of sweetsop's concentrate and carrageenan addition toward total phenol content, antioxidant activity, and preference level of flavor, color, aroma of sweetsop jelly yogurt.

Method: This research was a completely randomized two factor-experimental study. First, substitution of sweetsop's concentrate (10\%; 20\%; and 30\%). Second, carrageenan addition (0,7\% and 0,8\%) in the sweetsop jelly yogurt production. Analyze statistic of total phenol content and antioxidant activity using Two Way ANOVA test and be continued with Tukey test, whereas preference level using Friedman test and be continued with Wilcoxon test.

Result: The highest total phenol content on the substitution of 30\% sweetsop's concentrate and 0,7\% carrageenan addition was $88 \mathrm{mg}$ GAE, while the substitution of 30\% sweetsop's concentrate and $0,7 \%$ carrageenan had the highest antioxidant activity, 63\%. Carrageenan addition and substitution of sweetsop's concentrate increased the preference level of flavor but did not affect the preference of color and aroma.

Conclusion: Substitution of sweetsop's concentrate and carrageenan addition on functional drink, sweetsop jelly yogurt, increase total phenol content, antioxidant activity and preference level of flavor significantly.

Keywords: Functional drink, sweetsop, carrageenan, total phenol, antioxidant activity
\end{abstract}

\section{ABSTRAK}

Latar Belakang: Kadar LDL (Low Density Lipoprotein) yang tinggi merupakan salah satu faktor pemicu sindrom metabolik. Penurunan kadar LDL dapat melalui mekanisme antioksidan. Buah srikaya yang tinggi antioksidan diolah bersama susu sapi segar dengan penambahan karagenan menjadi minuman jelly yoghurt tinggi antioksidan yang dapat dijadikan minuman fungsional sebagai alternatif menurunkan resiko sindrom metabolik.

Tujuan: Menganalisis pengaruh substitusi sari srikaya dan penambahan karagenan terhadap kadar fenol total, aktivitas antioksidan dan tingkat kesukaan yang meliputi rasa,warna, aroma minuman fungsional jelly yoghurt srikaya.

Metode: Merupakan penelitian eksperimental rancangan acak lengkap dua faktor yaitu substitusi sari srikaya (10\%; 20\%; dan 30\%) dan penambahan karagenan (0,7\% dan 0,8\%) pada pembuatan minuman jelly yoghurt srikaya. Analisis statistik kadar fenol total dan aktivitas antioksidan menggunakan uji Two Way ANOVA dilanjutkan uji Tukey, sedangkan uji kesukaan menggunakan uji Friedman dilanjutkan uji Wilcoxon.

Hasil: Kadar fenol total tertinggi pada substitusi 30\% sari srikaya penambahan 0,7\% karagenan yaitu $88 \mathrm{mg}$ GAE sedangkan subsitusi 30\% sari srikayadan 0,7\% karagenan memiliki aktivitas antioksidan tertinggi sebesar $63 \%$. Penambahan karagenan dan substitusi sari srikaya meningkatkan kesukaan dalam rasa namun tidak mempengaruhi kesukaan dalam parameter warna dan aroma.

Simpulan: Substitusi sari srikaya dan penambahan karagenan pada minuman fungsional jelly yoghurt srikaya meningkatkan kadar fenol total, aktivitas antioksidan dan tingkat kesukaan rasa secara signifikan.

Kata kunci: minuman fungsional, srikaya, karagenan, fenol total, aktivitas antioksidan

\section{PENDAHULUAN}

Sindrom metabolik adalah kumpulan risiko terhadap penyakit kardiovaskuler dan kelainan metabolik yang meliputi peningkatan LDL (Low Density Lipoprotein), obesitas sentral, resistensi insulin, dislipidemia, hipertensi. ${ }^{1,2}$ Menurut NCEP ATP III (National Cholesterol Education Program Adult Treatment Panel III), seseorang dikatakan sindrom metabolik apabila memenuhi kriteria sebanyak tiga atau lebih. ${ }^{2}$

Prevalensi sindrom metabolik di Amerika Serikat pada orang dewasa berusia 20 tahun ratarata adalah 23,7\%. Pada penelitian di Bali, prevalensi sindrom metabolik rata- rata $20,3 \%$ dengan faktor rendahnya kolesterol HDL (High Density Lipoprotein) sebagai kriteria klinis tertinggi ${ }^{1}$. Rendahnya kolesterol HDL berhubungan

\footnotetext{
${ }^{*}$ Penulis Penanggungjawab
} 
erat dengan penyakit jantung koroner dibandingkan dengan kolesterol total dan LDL pada sindroma metabolik. ${ }^{1}$

Seseorang dengan sindrom metabolik mengalami stres oksidatif yang lebih tinggi dikarenakan pertahanan tubuh melalui sistem antioksidan berkurang. Stres oksidatif adalah keadaan ketidakseimbangan antara produksi ROS (reactive oxygen species) dan kemampuan mekanisme proteksi alami suatu organisme. ${ }^{22}$ Beberapa penelitian mengindikasikan faktor pemicu stres oksidatif adalah peningkatan jumlah radikal bebas yang dapat menyebabkan kerusakan sel dan jaringan dalam tubuh. ${ }^{2,4}$

Kerusakan oksidatif atau kerusakan akibat radikal bebas dalam tubuh pada dasarnya dapat diatasi oleh antioksidan endogen namun jika radikal bebas terdapat berlebih dalam tubuh atau melebihi batas kemampuan proteksi antioksidan seluler, maka dibutuhkan antioksidan tambahan dari luar atau antioksidan eksogen untuk menetralkan radikal yang terbentuk yang berasal dari makanan seharihari juga diperlukan untuk meminimalkan stres oksidatif. $^{5}$

Fenol sebagai antioksidan dapat menurunkan kadar kolesterol darah melalui mekanisme peningkatan kolesterol HDL. HDL berperan pada proses RCT (Reverse Cholesterol Transport) atau pengangkutan balik kolesterol, di mana HDL dapat meningkatkan efluks kelebihan kolesterol dari jaringan perifer dan mengembalikan ke hati untuk diekskresikan melalui empedu. ${ }^{6}$

Srikaya merupakan salah satu buah yang mengandung kadar fenol tinggi. Senyawa fenol yang tinggi pada buah srikaya meliputi epicatechin, quercetin dan kaempferol. Dari hasil penilitian, dalam 100 gram buah srikaya mengandung total fenol sebanyak 405,41 mg GAE. ${ }^{7}$

Yoghurt susu mengandung bakteri asam laktat yang berpotensi menurunkan kadar kolesterol LDL karena bakteri dalam produk tersebut menghasilkan asam-asam organik seperti asam glukoronat, asam propionat, asam folat dan asam laktat yang dapat berperan sebagai agen penurun kadar kolesterol LDL. ${ }^{8,9}$

Inulin merupakan prebiotik yang bersifat serat larut air air. Inulin tidak dapat dicerna oleh enzim pencernaan seperti $\alpha$-amilase atau enzim penghidrolisis lainnya baik pada $\mathrm{pH}$ rendah maupun tinggi. Oleh karena itu, inulin dapat sampai di usus dengan utuh sehingga dapat difermentasi probiotik. ${ }^{10}$ Penambahan inulin dapat membantu pertumbuhan bakteri asam laktat dan bersifat protektif terhadap probiotik sehingga meningkatkan ketahanan hidup dan aktivitas probiotik selama masa penyimpanan.

Berdasarkan beberapa penelitian sebelumnya didapatkan formulasi minuman fungsional jelly yoghurt srikaya yang terdiri dari konsentrasi sari buah srikaya, karagenan dan inulin. Pencampuran sari buah srikaya dengan yoghurt menggunakan metode substitusi sebesar 10\%,20\% dan $30 \%$. Penambahan karagenan sebesar $0,7 \%$ dan $0,8 \%$ karena konsentrasi tersebut merupakan konsentrasi terbaik berdasarkan uji organoleptik dan uji serat. ${ }^{21}$ Konsentrasi penambahan inulin yang terbaik pada penelitian sebelumnya adalah sebesar $4 \%$ berdasarkan uji organoleptik. ${ }^{15}$

Produk yoghurt srikaya akan diolah lebih lanjut menjadi minuman jelly dengan penambahan karagenan. Minuman jelly bermanfaat bagi pencernaan dan mengandung dietary fiber sehingga dapat menambah kandungan serat dalam yoghurt srikaya. Karagenan berfungsi sebagai penstabil, pengental, pembentuk gel dan sumber serat pangan untuk membantu memperlancar pencernaan. ${ }^{11}$ Tujuan penelitian ini adalah menganalisis pengaruh substitusi sari srikaya dan penambahan karagenan terhadap kadar fenol total, aktivitas antioksidan dan tingkat kesukaan rasa, warna dan aroma minuman fungsional jelly yoghurt srikaya. Perpaduan yoghurt srikaya yang diolah menjadi minuman jelly diharapkan dapat menghasilkan minuman fungsional bagi masyarakat yang tinggi serat, probiotik dan antioksidan sehingga dapat menurunkan resiko stres oksidatif.

\section{METODE}

Penelitian yang dilakukan termasuk dalam bidang food production. Penelitian dilalaksanakan pada bulan Juni hingga Juli 2015 di Laboratorium Ilmu Gizi dan Teknologi Pangan Universitas Muhammadiyah Semarang.

Penelitian ini merupakan penelitian eksperimental dengan rancangan acak lengkap dua faktor, yaitu substitusi sari srikaya $(10 \%, 20 \%$, dan $30 \%$ ) dan penambahan karagenan ( $0,7 \%$ dan $0,8 \%$ ) dengan tujuh kelompok perlakuan termasuk kontrol (tidak diberi substitusi sari srikaya dan penambahan karagenan). Masing-masing kelompok dilakukan pengulangan sebanyak 3 kali dengan analisis secara duplo meliputi analisis fenol total, aktivitas antioksidan dan tingkat kesukaan. Penentuan formulasi substitusi sari srikaya dan penambahan karagenan berdasarkan penelitian sebelumnya dengan produk minuman jelly yoghurt stroberi. ${ }^{21}$ 
Tabel 1. Formulasi Bahan Minuman Fungsional Jelly Yoghurt Srikaya

\begin{tabular}{ccc}
\hline Sari Buah Srikaya $(\mathrm{S})$ & \multicolumn{2}{c}{ Karagenan $(\mathrm{K})$} \\
\cline { 2 - 3 } & $0,7 \%(\mathrm{~K} 1)$ & $0,8 \%(\mathrm{~K} 2)$ \\
\hline $10 \%(\mathrm{~S} 1)$ & $\mathrm{S} 1 \mathrm{~K} 1$ & $\mathrm{~S} 1 \mathrm{~K} 2$ \\
$20 \%(\mathrm{~S} 2)$ & $\mathrm{S} 2 \mathrm{~K} 1$ & $\mathrm{~S} 2 \mathrm{~K} 2$ \\
$30 \%(\mathrm{~S} 3)$ & $\mathrm{S} 3 \mathrm{~K} 1$ & $\mathrm{~S} 3 \mathrm{~K} 2$ \\
\hline
\end{tabular}

Proses pembuatan minuman jelly yoghurt srikaya melalui tahap pasteurisasi susu sapi segar dengan penambahan inulin sebagai prebiotik hingga suhu $90^{\circ} \mathrm{C}$ lalu didinginkan hingga suhu $45^{\circ} \mathrm{C}$ dan ditambahkan sari srikaya dan starter $3 \%$ Lactobacillus bulgarius dan Streptococcus themophilus. Proses selanjutnya adalah inkubasi selama 6-18 jam dengan suhu $40^{\circ} \mathrm{C}$. Setelah proses inkubasi selesai, yoghurt srikaya diberi tambahan karagenan untuk membentuk tekstur jelly pada minuman.

Buah srikaya didapatkan di Semarang, inulin didapatkan dari Laboratorium Teknologi Pangan Ilmu Gizi Universitas Diponegoro, karagenan didapakan dari Lansida Yogyakarta, bakteri Lactobacillus bulgarius dan Streptococcus themophilus didapatkan dari PAU Universitas Gadjah Mada Yogyakarta.

Pada penelitian ini dilakukan pengumpulan data total fenol dengan metode kalorimetri, aktivitas antioksidan dengan metode DPPH dan uji kesukaan pada 25 panelis agak terlatih, mahasiswa Program Studi Ilmu Gizi Fakultas Kedokteran Universitas Diponegoro.

Data yang terkumpul selanjutnya dilakukan analisis menggunakan program SPSS. Pengaruh variasi persentase substitusi sari srikaya dan penambahan karagenan terhadap kadar fenol total dan aktivitas antioksidan diuji dengan Two Ways Anova. Analisis untuk mengetahui beda nyata perlakuan digunakan uji Tukey dan analisis pada tingkat kesukaan digunakan uji Friedman dengan uji lanjut uji Wilcoxon Signed Ranks Test. ${ }^{12}$

\section{HASIL \\ Kadar Fenol Total}

Hasil analisis kadar fenol total minuman fungsional jelly yoghurt srikaya dapat dilihat pada Tabel 2.

Tabel 2. Hasil analisis kadar fenol total(mg GAE) minuman fungsional jelly yoghurt srikaya

\begin{tabular}{cccc}
\hline & \multicolumn{3}{c}{ Karagenan } \\
\cline { 2 - 4 } Sari Srikaya & $\mathbf{0 \%}$ & $\mathbf{0 , 7} \%$ & $\mathbf{0 , 8} \%$ \\
\hline $0 \%$ & $16 \pm 0.027^{\mathrm{e}}$ & \\
$10 \%$ & & $61 \pm 0,267^{\mathrm{c}}$ & $46 \pm 0,045^{\mathrm{d}}$ \\
$20 \%$ & & $76 \pm 0,015^{\mathrm{b}}$ & $62 \pm 0,100^{\mathrm{c}}$ \\
$30 \%$ & & $88 \pm 0,025^{\mathrm{a}}$ & $79 \pm 0,005^{\mathrm{b}}$ \\
\hline
\end{tabular}

Keterangan: Angka yang diikuti huruf superscript berbeda (a,b,c,d) menunjukkan beda nyata

Berdasarkan analisis statistik Friedman substitusi sari srikaya dan penambahan karagenan meningkatkan kadar fenol total secara signifikan dengan nilai $\mathrm{p}=0,007$. Penambahan $0,7 \%$ karagenan memiliki kadar fenol yang lebih tinggi dibandingkan penambahan 0,8\% karagenan.

Minuman fungsional jelly yoghurt srikaya dengan substitusi 30\% sari srikaya dan penambahan
$0,7 \%$ karagenan memiliki kadar fenol total tertinggi sebesar 88 mg GAE. Semakin banyak substitusi sari srikaya, kadar fenol total meningkat.

\section{Aktivitas Antioksidan}

Aktivitas antioksidan minuman fungsional jelly yoghurt srikaya dapat dilihat pada Tabel 3 .

Tabel 3. Hasil analisis aktivitas antioksidan(\%) minuman fungsional jelly yoghurt srikaya

\begin{tabular}{cccc}
\hline & \multicolumn{3}{c}{ Karagenan } \\
\cline { 2 - 4 } Sari Srikaya & $\mathbf{0 \%}$ & $\mathbf{0 , 7} \%$ & $\mathbf{0 , 8} \%$ \\
\hline $0 \%$ & $4,08 \pm 2,05^{\mathrm{f}}$ & $37,44 \pm 1,89^{\mathrm{c}}$ & $20,96 \pm 0,88^{\mathrm{e}}$ \\
$10 \%$ & & $51,91 \pm 1,88^{\mathrm{b}}$ & $32,37 \pm 1,99^{\mathrm{d}}$ \\
$20 \%$ & & $63,81 \pm 1,50^{\mathrm{a}}$ & $48,43 \pm 1,26^{\mathrm{b}}$ \\
\hline $0 \%$ & &
\end{tabular}

Keterangan: Angka yang diikuti huruf superscript berbeda $(\mathrm{a}, \mathrm{b}, \mathrm{c}, \mathrm{d})$ menunjukkan beda nyata

Semakin banyak substitusi sari srikaya maka aktivitas antioksidan semakin meningkat.
Berdasarkan analisis statistik menggunakan Two ways anova menunjukkan bahwa substitusi sari 
srikaya dan penambahan karagenan meningkatkan aktivitas antioksidan secara signifikan $(\mathrm{p}=0,00)$. Penambahan karagenan 0,8\% menurunkan aktivitas antioksidan dibandingkan penambahan karagenan $0,7 \%$. Interaksi antara sari srikaya dan karagenan tidak meningkatkan aktivitas antioksidan secara signifikan $(\mathrm{p}=0,123)$.

Penambahan sari srikaya dan penambahan karagenan menunjukkan hasil berbeda secara signifikan terhadap minuman kontrol. Berdasarkan Tabel 2, kandungan antioksidan tertinggi terdapat pada minuman dengan substitusi $30 \%$ sari srikaya penambahan $0,7 \%$ karagenan.

\section{Tingkat Kesukaan}

Rasa

Hasil analisis tingkat kesukaan rasa minuman fungsional jelly yoghurt srikaya dapat dilihat pada Tabel 4.

Tabel 4. Hasil analisis tingkat kesukaan rasa minuman fungsional jelly yoghurt srikaya

\begin{tabular}{cccc}
\hline Sari & \multicolumn{3}{c}{ Karagenan } \\
\cline { 2 - 4 } Srikaya & \multicolumn{1}{c}{$\mathbf{0 \%}$} & \multicolumn{1}{c}{$\mathbf{0 , 7} \%$} & \multicolumn{1}{c}{$\mathbf{0 , 8} \%$} \\
\hline $0 \%$ & $1,72 \pm 1,06^{\mathrm{f}}($ tidak suka) & & \\
$10 \%$ & & $2,00 \pm 1,12^{\mathrm{ef}}($ agak tidak suka) & $2,44 \pm 1,28^{\mathrm{de}}$ (agak tidak suka) \\
$20 \%$ & & $3,00 \pm 1,08^{\mathrm{bd}}($ netral) & $2,96 \pm 1,12^{\mathrm{cd}}$ (netral) \\
$30 \%$ & $3,60 \pm 1,45^{\mathrm{bc}}($ agak suka) & $3,92 \pm 1,26^{\text {a }}$ (agak suka) \\
\hline
\end{tabular}

Keterangan: Angka yang diikuti huruf superscript berbeda $(\mathrm{a}, \mathrm{b}, \mathrm{c}, \mathrm{d})$ menunjukkan beda nyata

Hasil uji kesukaan terhadap rasa pada minuman dengan substitusi $30 \%$ sari srikaya dan penambahan $0,8 \%$ karagenan memiliki tingkat kesukaan tertinggi yaitu 3,92 (agak suka). Analisis Friedman menunjukkan substitusi sari srikaya dan penambahan karagenan meningkatkan tingkat kesukaan rasa minuman fungsional secara signifikan $(\mathrm{p}=0,00)$. Semakin banyak substitusi sari srikaya dan penambahan karagenan maka tingkat kesukaan terhadap rasa minuman semakin meningkat.

\section{Warna}

Analisis tingkat kesukaan rasa minuman fungsional jelly yoghurt srikaya dapat dilihat pada Tabel 5.

Tabel 5. Hasil analisis tingkat kesukaan warna minuman fungsional jelly yoghurt srikaya

\begin{tabular}{cccc}
\hline Sari & \multicolumn{3}{c}{ Karagenan } \\
\cline { 2 - 4 } Srikaya & $\mathbf{0 \%}$ & $\mathbf{0 , 7} \%$ & $\mathbf{0 , 8} \%$ \\
\hline $0 \%$ & $3,60 \pm 1,12$ & $3,80 \pm 0,96$ & $3,52 \pm 1,12$ \\
$10 \%$ & & $3,72 \pm 1,02$ & $3,52 \pm 1,09$ \\
$20 \%$ & & $3,72 \pm 1,13$ & $3,68 \pm 1,03$ \\
$30 \%$ & & & \\
\hline
\end{tabular}

Keterangan: Angka yang diikuti huruf superscript berbeda (a,b,c,d) menunjukkan beda nyata

Berdasarkan hasil analisis Friedman substitusi sari srikaya dan penambahan karagenan tidak berpengaruh terhadap tingkat kesukaan warna minuman $(\mathrm{p}=0,29)$. Minuman yang memiliki tingkat kesukaan warna tertinggi yaitu substitusi $10 \%$ sari srikaya dan penambahan $0,7 \%$ karagenan sebesar 3,80(agak suka) sedangkan minuman dengan substitusi $20 \%$ sari srikaya dan penambahan
$20 \%$ karagenan memiliki tingkat kesukaan warna yang paling rendah.

\section{Aroma}

Hasil analisis tingkat kesukaan rasa minuman fungsional jelly yoghurt srikaya dapat dilihat pada Tabel 6.

Tabel 6. Hasil analisis tingkat kesukaan aroma minuman fungsional jelly yoghurt srikaya

\begin{tabular}{cccc}
\hline Sari & \multicolumn{3}{c}{ Karagenan } \\
\cline { 2 - 4 } Srikaya & $\mathbf{0 \%}$ & $\mathbf{0 , 7} \%$ & $\mathbf{0 , 8} \%$ \\
\hline $0 \%$ & $2,72 \pm 1,24$ & $3,28 \pm 1,31$ & $3,20 \pm 1,08$ \\
$10 \%$ & & $2,68 \pm 1,11$ & $2,96 \pm 1,17$ \\
$20 \%$ & & $3,16 \pm 1,46$ & $3,24 \pm 1,42$ \\
$30 \%$ & & &
\end{tabular}

Keterangan: Angka yang diikuti huruf superscript berbeda (a,b,c,d) menunjukkan beda nyata

Substitusi sari srikaya dan penambahan karagenan tidak berpengaruh terhadap tingkat kesukaan aroma minuman $(\mathrm{p}=0,14)$. Minuman dengan substitusi $30 \%$ sari srikaya dan penambahan 
0,8\% karagenan memiliki tingkat kesukaan aroma tertinggi sebesar 3,24 (netral).

\section{PEMBAHASAN \\ Kadar Fenol Total, Aktivitas Antioksidan dan Tingkat Kesukaan Minuman Fungsional Jelly Yoghurt Srikaya \\ Kadar Fenol Total}

Hasil uji statistik menunjukkan bahwa substitusi sari srikaya sebanyak $10 \%, 20 \%, 30 \%$ dan penambahan karagenan $0,7 \%$ dan $0,8 \%$ berbeda secara signifikan terhadapan minuman kontrol. Kadar fenol total tertinggi terdapat pada substitusi $30 \%$ sari srikaya dan penambahan $0,7 \%$ karagenan sebesar 88 mg GAE.

Substitusi sari srikaya meningkatkan kadar fenol total minuman fungsional jelly yoghurt srikaya. Hal ini disebabkan susu sapi mengandung senyawa fenol atau jenis antioksidan lain seperti $\alpha$ tokoferol, karatenoid, kasein dan laktoferin sehingga kombinasi sari srikaya dan susu sapi menjadi yoghurt dapat meningkatkan total fenol minuman jelly yoghurt.

Penambahan karagenan meningkatkan kadar fenol total minuman fungsional jelly yoghurt srikaya. Karagenan 0,8\% menurunkan kadar fenol total jika dibandingkan dengan penambahan karagenan $0,7 \%$ karena penambahan karagenan akan menambah senyawa hidrogen pada rantai fenolik sehingga pada konsentrasi yang tinggi senyawa fenolik tidak stabil dan menurun. ${ }^{14,15}$

Berdasarkan USDA (US Departement Agriculture) rekomendasi fenolik dari asupan adalah $6 \mathrm{mg} /$ hari untuk laki- laki dan 15,1mg/ hari untuk perempuan sedangkan rekomendasi flavonoid quercetin untuk laki- laki $8,2 \mathrm{mg} / \mathrm{hari}$ untuk perempuan $9,1 \mathrm{mg} /$ hari. ${ }^{23}$ Fenol sebagai antioksidan dapat menurunkan kadar kolesterol darah melalui mekanisme peningkatan kolesterol HDL. HDL berperan pada proses Reverse Cholesterol Transport (RCT) atau pengangkutan balik kolesterol, HDL dapat meningkatkan efluks kelebihan kolesterol dari jaringan perifer dan mengembalikan ke hati untuk diekskresikan melalui empedu. ${ }^{6}$ Berdasarkan beberapa penelitian fenol berperan sebagai antioksidan juga menurunkan kadar LDL yang teroksidasi. Senyawa fenol yang terdapat pada buah srikaya adalah flavonoid berupa epicatechin, quercetin dan kaempferol dapat berfungsi menurunkan disfungsi endotel, menurunkan peroksidase lemak. ${ }^{6,16}$

\section{Aktivitas Antioksidan}

Substitusi sari srikaya meningkatkan aktivitas antioksidan minuman fungsional jelly yoghurt srikaya. Antioksidan pada sari srikaya mampu melakukan penghambatan pembentukan senyawa radikal dengan baik, sehingga semakin banyak sari srikaya, semakin tinggi aktivitas antioksidannya.

Penambahan karagenan 0,8\% mempunyai aktivitas antioksidan yang lebih rendah karena aktivitas antioksidan berbanding lurus dengan total fenol, jika total fenol lebih rendah maka aktivitas antioksidan juga lebih rendah. ${ }^{17,20}$

Hasil uji statistik menunjukkan bahwa substitusi sari srikaya dan penambahan karagenan berbeda secara signifikan terhadapan minuman kontrol. Kadar antioksidan tertinggi terdapat pada substitusi $30 \%$ sari srikaya dan penambahan $0,7 \%$ karagenan sebesar $63,81 \%$.

Asupan antioksidan sangat diperlukan agar dapat meminimalisir stres oksidatif sehingga dapat mengurangi resiko sindrom metabolik. Aktivitas antioksidan merupakan parameter yang dapat menggambarkan persentase kemampuan suatu bahan makanan dalam menghambat radikal bebas. Aktivitas antioksidan pada minuman jelly yoghurt srikaya tidak hanya didapatkan dari total fenol saja melainkan dari semua jenis antioksidan yang terkandung di dalam minuman jelly yoghurt srikaya. Stres oksidatif menyebabkan ketidakseimbangan antioksidan dan radikal bebas karena terjadi kerusakan pada sel dan jaringan tubuh yang merupakan awal stres oksidatif. Senyawa flavonoid pada srikaya juga berperan sebagai antioksidan dengan mengikat ion-ion metal $(\mathrm{Fe}, \mathrm{Cu})$ yang dapat mengkatalisis reaksi yang memproduksi radikal bebas. ${ }^{18}$

\section{Tingkat Kesukaan}

Rasa

Hasil analisis tingkat kesukaan rasa minuman fungsional jelly yoghurt srikaya menunjukkan bahwa semakin banyak substitusi sari srikaya dan penambahan karagenan maka meningkatkan kesukaan panelis. Tingkat kesukaan tertinggi adalah substitusi $30 \%$ sari srikaya 0,8\% karagenan sebesar 3,92 (agak suka). Rasa buah srikaya kurang manis sehingga saat diolah menjadi minuman jelly yoghurt rasa yang dihasilkan juga kurang manis. Karagenan mempunyai rasa amis khas rumput laut, namun dapat hilang setelah diolah menjadi yoghurt.

\section{Warna}

Substitusi sari srikaya dan penambahan karagenan tidak berpengaruh pada tingkat kesukaan warna. Sari srikaya dan karagenan yang berwarna putih diolah bersama susu sapi yang berwarna putih tidak memberikan penambahan warna lain sehingga produk yang dihasilkan tetap berwarna putih. 


\section{Aroma}

Aroma yang dihasilkan pada kelompok perlakuan adalah aroma srikaya dan kelompok kontrol adalah aroma susu yang menyengat. Substitusi sari srikaya dan penambahan karagenan tidak berpengaruh pada tingkat kesukaan aroma.

\section{SIMPULAN}

Substitusi sari srikaya dan penambahan karagenan pada minuman fungsional jelly yoghurt srikaya meningkatkan kadar fenol total, aktivitas antioksidan dan tingkat kesukaan rasa secara signifikan dan tidak mempengaruhi tingkat kesukaan warna dan aroma.

Minuman dengan substitusi 30\% sari srikaya dan penambahan $0,7 \%$ karagenan memiliki total fenol dan aktivitas antioksidan tertinggi. Substitusi $30 \%$ sari srikaya dan penambahan $0,8 \%$ karagenan memiliki tingkat kesukaan rasa tertinggi.

\section{DAFTAR PUSTAKA}

1. Mohammad, SR. Patogenesis dan Terapi Sindroma Metabolik. J Kardiologi Indonesia. 2007;28:160168.

2. Ozbek, M., E Cakir and E Ozkaya. Oxidative Stress Markers in Metabolic Syndrome. Turkish Journal of Endocrinology and Metabolism.2011;15:57-61.

3. Waloya, T., Rimbawan dan $\mathrm{N}$ Andarwulan. Hubungan antara Konsumsi Pangan dan Aktivitas Fisik dengan Kadar Kolesterol Darah Pria dan Wanita Dewasa di Bogor. Jurnal Gizi dan Pangan. Maret 2013;8.

4. Wirakmono. Sindrom Metabolik. Jurnal Kedokteran Indonesia. 35(10): 10-26. 2006

5. Sulistiyowati, Y. Pengaruh Pemberian Likopen pada Status Antioksidan Tikus Hiperkolesterolemik. Program Studi Magister Ilmu Biomedik. Universitas Diponegoro.2006

6. Uto-Kondo, H., Ayaori M, Ogura M, Nakaya K, Ito M, Suzuki A, Takiguchi SI, Yakushiji E, Terao Y,Ozasa H, Hisada T, Sasaki M, Ohsuzu F and Ikewaki K. Coffee consumption enhances highdensity lipoprotein-mediated cholesterol efflux in macrophages. Circ Res. 2010; 106:779 -787.

7. Li Fu, B Tao Xu, X Rong Xu, R You Gan, Y Zhang, E Qin Xia, et al. Antioxidant capacities and total phenolic contents of 62 fruits. J of Food Chemistry 2011; 129: 345-350

8. Nakamura,Y., Kaihara A. Yoshii K, Tsumura Y, Ishimitsu $\mathrm{S}$ and Tonogai $\mathrm{Y}$. Content and composition of isoflavonoids in mature or immature beans and bean sprouts consumed in japan. Journal of Health Science. 2001; 47(4):394-406.

9. Wu, Z., L Song and D Huang. Polyphenolic antioxidants and phytoalexins changes in germinating legume seeds with food grade fungal Rhizopus oligoporus Stress. 2011.
10. Ichwansyah,R. Pengembangan Yoghurt Sinbiotik Plus Berbasis Puree Pisang Ambon dengan Penambahan Inulin sebagai Alternatif Pangan Fungsional. Departemen Gizi Masyarakat Fakultas Ekologi Manusia. Institus Pertanian Bogor.2014

11. Panca, IS. Sifat Kimia dan Viskositas Minuman Jelly Berbahan Baku Probiotik Selama Penyimpanan pada Suhu $4-7^{\circ} \mathrm{C}$. Program Studi Teknologi Hasil Ternak. Fakultas Peternakan. Institut Pertanian Bogor.2007

12. Dahlan, MS. Statistik untuk Kedokteran dan Kesehatan. Jakarta: Salemba Medika. 2013

13. Javanmardi, J., S Locke E and Vicanco JM. Antioxidant activity and total phenol content of Iranian Ocimum Accessions. J. Food Chem 83(1):547-550. 2003

14. Hijaz, MN. Uji Aktivitas Antioksidan Karagenan dalam Alga Merah Jenis Eucheuma spinosum dan Gracillaria verrucosa. Jurusan Kimia Fakultas Sains dan Teknologi. Universitas Islam Negri Malang. 2009

15. Morris, ER., K Nishinari and M Rinaudo. Gelation of Gellan. Journal Food Hydrocolloids. 2012; 28:373-411.

16. Almeida, MMB., P Henrique Machoda de Sousa, A Martha Campos Arriaga, G Matias do Prado, C Emanuel de Caevalho, G Arreas, et al. Bioactive Compounds and Antioxidant activity of Fresh Exotic Fruits from Norheastern Brazil. J Food Research Internasional.2011;44: 2155-2159

17. Kao, MS. Phenolic content and antioxidant capacities of Alabama-Grown thornless blackberries. Int J Fruit Sci. 2007; 7:33-46

18. Mira, L., MT Fernandez and M Santos. Interactions of Flavonoids with Iron and Copper Ions: mechanism for their antioxidant activity. Free Radic Res 2002; 36(11):1199-1208

19. Vatai, T., M Skerget and Z Knez. Extraction of Phenolic Compounds from Elder berry and Different Grape Marc Varieties Using Organic Solvents and/Or Supercritical Carbon Dioxide. $J$. Food Eng.2009

20. Kalt, W., JE Mcdonald and $\mathrm{H}$ Donner. Anthocyanins, Phenolics And Antioxidant Capacity Of Processed Lowbush Blueberry Products. J. Food Science. 2000

21. Hapsari, AP. Formulasi dan Karakterisasi Minuman Fungsional Fruity Jelly Yoghurt Berbasis Kappa Karagenan sebagai Sumber Serat Pangan. Program Studi Teknologi Hasil Perairan. Fakultas Perikanan dan Ilmu Kelautan. Institut Pertanian Bogor;2011.

22. Grober, U. Mikronutrien Penyelarasan Metabolik, Pencegahan dan Terapi. Jakarta: EGC. 2012

23. Dasgupta, A and K Klein. Antioxidants in Food, Vitamins and Supplements Prevention and Treatment of Disease. Elsevier. 2014. p 230-231 